\title{
Errata
}

\section{Cloning of Clostridium acetobutylicum genes and their expression in Escherichia coli and Bacillus subtilis}

Irène Efstathiou and Nicole Truffaut

Unité des Anaérobies, Institut Pasteur, 25, rue du Dr. Roux, F-75724 Paris Cedex 15, France

Mol Gen Genet (1986) 204:317-321

In the sections headed "Complementation of auxotrophs" and "Transformation of a Bacillus subtilis strain for leucine prototrophy" as well as in the final paragraph of the paper, $\alpha$ isopropyl malate dehydrogenase should read $\beta$ isopropyl malate dehydrogenase.

Also in the section on "Complementation of auxotrophs", $\alpha$ glutamyl phosphate reductase should read $\gamma$ glutamyl phosphate reductase. 